\title{
MENSAJE DE LOS EDITORES
}

Estimados lectores,

Deseamos informarles de algunas actividades realizadas para dar mayor formalidad y difusión al Boletín DE LA Sociedad GEOLÓGICA MeXiCANA.

La primera de ellas ha sido el nombramiento de un equipo editorial formado por cinco editores científicos y por un comité editorial integrado por especialistas de diversas disciplinas e instituciones.

Para dar mayor difusión a los trabajos, a partir del tomo LIV se publica la versión electrónica del Boletín en la página de Internet de la SGM: http://www.geociencias.unam.mx/ SGM.html. Además se ha realizado un gran esfuerzo para rescatar todos los trabajos publicados en el Boletín desde su primera publicación en 1904. Como parte de las actividades para conmemorar el primer centenario de la SGM, se recuperaron en versión digital 417 trabajos publicados en 53 tomos del Boletín. Estos trabajos se colocaron para su consulta en la página web de la SGM y también pueden ser adquiridos en disco compacto.

En cuanto al contenido del presente número, se incluye un trabajo de Odranoel QuinteroLegorreta, el cual fue sometido al Boletín por el autor poco antes de su deceso. Decidimos publicar este trabajo en reconocimiento a la labor realizada por Odranoel en estudios de Neotectónica en México, para lo cual Javier Arellano Gil y Susana A. Alaniz Alvarez colaboraron en la revisión y corrección del trabajo y Max Suter proporcionó algunas figuras complementarias.

En este tomo aparece la segunda parte de un extenso trabajo sobre la historia tectónica de la cuenca de Chihuahua realizado por Water T. Haenggi. De acuerdo con los estatutos de la SGM, los trabajos publicados en el Boletín deben ser escritos en español, pero debido a la relevancia del trabajo consideramos adecuado hacer una excepción y permitir su publicación en inglés.

Esperamos que los cambios realizados en la organización de nuestro Boletín permitan mejorar su calidad, difusión, y regularidad, así como disminuir los tiempos de publicación.

Juriquilla, Qro., a 13 de Diciembre de 2002

Por los editores

Ma. Teresa Orozco-Esquivel 